\title{
Delimitação de Área de Proteção Permanente (APP) no entorno das represas Paraibuna-Paraitinga, São Paulo.
}

\author{
Patrick Thomaz de Aquino Martins ${ }^{1}$ \\ Joselisa Maria Chaves ${ }^{2}$ \\ ${ }^{1}$ Universidade Estadual Paulista - UNESP \\ Avenida 24-A, 1515, Bela Vista - 13.506-900 - Rio Claro - SP, Brasil \\ patrick_thomaz@yahoo.com.br \\ ${ }^{2}$ Universidade Estadual de Feira de Santana - UEFS. \\ Km 03, BR 116 - Cidade Universitária - 44.031-460 - Feira de Santana - BA, Brasil \\ joselisa@uefs.br
}

\begin{abstract}
The aim of this research is to delimit Permanent Protection Areas around the dams of Paraibuna and Paraitinga, São Paulo State. It was established a buffer of $100 \mathrm{~m}$ and it was analyzed the vegetal covering distribution and also the current use of the ground. It was verified a pattern of land use and vegetation cover in both reservoirs (Paraibuna-Paraitinga), characterized by the predominance of class pasture/agriculture (61\%), followed of forest/"capoeira" (24\%), and eucalyptus, (10\%). The remaining percentage was represented by the classes unit urban, exposed soil and water. Since this area generates significantly economic resources to municipalities, a management plan for it is necessary. The permanence of the current landscape around the dams may have direct negative impact on water quality and adversely affect the water supply to municipalities served by it.
\end{abstract}

Palavras-chave: geotecnologies, Permanent Protection Areas, Brazilian Forest Code, mapping. geotecnologias, Área de Proteção Permanente, Código Florestal brasileiro, mapeamento 


\section{Considerações iniciais}

Devido ao ano de aprovação do Código Florestal brasileiro, (BRASIL, 1934) e à posterior institucionalização do mesmo, o qual traz consigo a definição de APP (BRASIL, 1965), a ofensiva antrópica aos remanescentes florestais naturais no Brasil já possuíam um estágio de degradação avançado no final do século XX. Com a delimitação das Áreas de Proteção Permanente (APP) no entorno de represas sendo publicada apenas no ano de 2002, a partir de uma resolução do Conselho Nacional do Meio Ambiente, CONAMA (BRASIL, 2002), essa ofensiva persistiu ainda no início do presente século.

A presença de áreas protegidas legalmente implica no impedimento de ações degradantes, como o corte, a exploração, a supressão da vegetação, ou qualquer outro tipo de agressão ambientalmente danoso a esse espaço (MARTINS, 2008).

De acordo com Prado (2004), a ocupação irregular das margens dos reservatórios e mudanças de uso e cobertura do solo nas suas bacias podem afetar a qualidade da água destes reservatórios. Uma ação que poderia evitar esse cenário está relacionada ao cumprimento da legislação vigente, notadamente o Código Florestal brasileiro.

Nesse sentido, o presente estudo teve como objetivo identificar a atual situação da cobertura vegetal e uso do solo, com base no Código Florestal brasileiro e Resolução CONAMA n $n^{\circ}$ 302/02, no entorno das represas de Paraibuna e Paraitinga, Estado de São Paulo, a partir de técnicas de geoprocessamento.

\section{Caracterização da área de estudo}

As Represas de Paraibuna e Paraitinga estão localizadas na Bacia Hidrográfica do Alto Vale do Paraíba (BHAVP), leste do Estado de São Paulo, inserindo-se na Bacia do Rio Paraíba do Sul em escala regional.

Os reservatórios de Paraibuna e Paraitinga são conectados geograficamente ao ponto de terem suas águas confundidas (Figura 1), formando um único espelho d'água. Para que isso acontecesse, uma porção do relevo que dividia as duas barragens foi dinamitada, formando um canal que os interliga (DIAS et al., 2007). Deste modo, ambas as represas são tratadas como uma só, Paraibuna-Paraitinga, distinção também adotada no presente estudo.

As represas Paraibuna-Paraitinga compreendem parte do território dos municípios de Paraibuna, Redenção da Serra e Natividade da Serra (Figura 1), os quais somam cerca de 27.812 habitantes (IBGE, 2007). Os principais tributários que deságuam nessa represa são o Rio Paraibuna, o Rio Paraitinga e o Ribeirão Fartura.

A geologia da área é formada majoritariamente pelo Complexo costeiro (Proterozóico) e Corpos de granito (Fanerozóico e Proterozóico). Também são encontradas as unidades de Xistos (Proterozóico), Ortognáissicas (Proterozóico), Paragnáissica (Proterozóico) e o Complexo Rio Capivari (Arqueano) (IBGE, 2008).

Geomorfologicamente, são características as formações de morro, sejam paralelos, em mares de morros ou com serras restritas, além de escarpas com espigões digitados e colinas pequenas com espigões locais (IBAMA, 2008).

Em linhas gerais, tomando como referência o primeiro nível categórico do sistema brasileiro de classificação de solos (EMBRAPA, 1999), há o predomínio de argissolos, latossolos e cambissolos (IBAMA, 2008).

\section{Materiais e métodos}

\subsection{Materiais}

Foram utilizados uma imagem Landsat, sensor TM, ponto 218, órbita 076, de 16 de janeiro de 2008; um mosaico de imagem Landsat ortorretificada do programa GeoCover, - 
10_2000; e um conjunto de cenas CBERS-2B, sensor HRC, datadas de 13 de julho de 2008, ponto 153 , órbita $126(3,4$ e 5$)$.

Os aplicativos utilizados no tratamento dessas imagens, bem como na construção do banco, foram executados em computador PC. Fez-se uso do ArcGIS 9.2, do Global Mapper 10 e do SPRING 5.0.2 (CÂMARA et al., 1996), incluindo o módulo Impima 5.0.

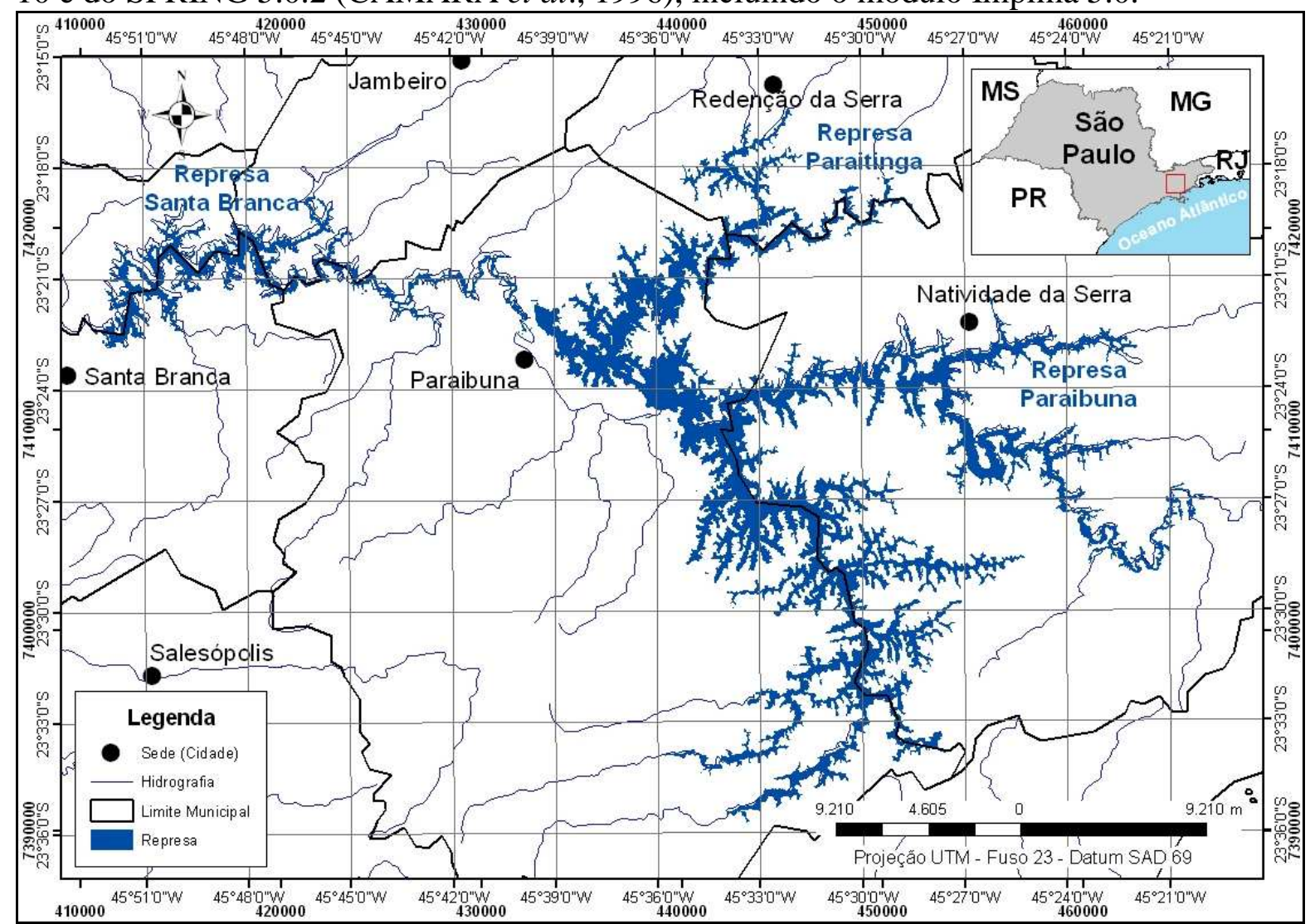

Figura 1 - Localização das represas de Santa Branca, Paraibuna e Paraitinga.

Fonte: Adaptado de IBAMA (2008), IBGE (2008), PDI.

\subsection{Aquisição e organização dos dados}

As imagens foram adquiridas a partir da rede mundial de computadores (internet), via FTP. Através da base de dados da Divisão de Geração de Imagens/Instituto Nacional de Pesquisas Espaciais (DGI/INPE, 2008) foram obtidas as imagens Landsat e CBERS-2B, ambas em formato GeoTIFF.

A partir do sitio GeoCover (NASA, 2008), foi realizado o download do mosaico de imagem correspondente a área de estudo, em extensão MrSID, a qual foi utilizada como base à correção geométrica das imagens Landsat na fase de pré-processamento.

\subsection{Pré-processamento}

Construiu-se um banco de dados, utilizando como gerenciador o sistema dbase, e estabeleceu-se o projeto de execução utilizando-se a projeção Universal Transversa de Mercator, UTM. Como Sistema Geodésico de Referência, empregou-se o South American Datum1969, SAD-69.

Devido à incompatibilidade do SPRING 5.0.2 com o formato da imagem GeoCover (formato MrSID), foi feito o uso do aplicativo Global Mapper 10 para a exportação do GeoCover em extensão GeoTIFF e mudança do sistema de projeção, a qual foi importada ao SPRING 5.0.2, integrando-se ao banco de dados. 
A partir da imagem GeoCover identificaram-se pontos de controle, GCPs (Ground Control Points), e procedeu-se a correção geométrica das imagens, adotando-se a projeção UTM e datum SAD-69. A função polinomial aplicada foi a de $3^{\mathrm{a}}$ ordem e interpolador bilinear. Foram amostrados 15 GCPs, adotando-se como padrão os erros médios quadráticos RMS, inferiores a um 0.5 pixel, resultando em 0,271 (8,13m) de Erro Médio Quadrático geral (RMS).

\subsection{Realce}

O realce da imagem compreendeu três fases: a escolha da tríade à composição colorida, a aplicação de realce de contraste e a segmentação. No primeiro caso, a combinação foi obtida a partir do cálculo do OIF (Optimum Index Factor), conforme Chavez Jr. et al. (1982). A tríade mais bem classificada foi composta pelas bandas 1, 4 e 5. Estas foram comparadas com as demais, a partir de testes visuais de combinações nos diferentes canais, elegendo a combinação 4R5G1B como a ideal à execução do trabalho.

Como realce de contraste, foi aplicado o contraste linear. Após a aplicação do contraste foi utilizada a técnica de segmentação, algoritmo de crescimento de regiões, com valores de limiar de similaridade e de área, respectivamente, de 25 e 15. As imagens foram então submetidas à classificação supervisionada.

As regiões de classes temáticas foram consideradas com base no conhecimento prévio da área de estudo e na imagem do sensor HRC, do satélite CBERS 2B, na qual foi aplicado apenas um contraste linear.

\subsection{Processamento}

A etapa de processamento envolveu a classificação supervisionada com o algoritmo Bhattacharya, utilizando o limiar de aceitação de 99\%. As imagens classificadas foram convertidas em imagem temática, atribuindo-se cores característica às classes.

\subsection{Pós-processamento}

As imagens temáticas foram transformadas em dados vetoriais, exportadas em formato shapefile e abertas no aplicativo ArcGIS 9.1, onde foi realizada a delimitação de buffers da APP, associação com uma base cartográfica e alimentação do banco de dados.

A delimitação das APPs em torno dos reservatórios seguiu as especificações contidas no Código Florestal brasileiro (BRASIL, 1965) e na Resolução CONAMA n 302/02 (BRASIL, 2002).

As classes identificadas na classificação foram transformadas em classes secundárias, obedecendo aos critérios disponíveis na legislação vigente. As classes tiveram seus layouts de apresentação e representações gráficas organizados e foram analisados.

\section{Resultados e discussão}

\subsection{O Código Florestal brasileiro e as APPs nas represas}

As larguras mínimas consideradas APPs no entorno de reservatórios são de trinta metros para os reservatórios artificiais situados em áreas urbanas consolidadas e cem metros para áreas rurais; quinze metros, no mínimo, para os reservatórios artificiais de geração de energia elétrica com até dez hectares, sem prejuízo da compensação ambiental; quinze metros, no mínimo, para reservatórios artificiais não utilizados em abastecimento público ou geração de energia elétrica, com até vinte hectares de superfície e localizados em área rural (BRASIL, 2002). 
No caso específico das represas Paraibuna-Paraitinga, destinadas ao abastecimento público, geração de energia elétrica e possui mais de vinte hectares de superfície (SÃO PAULO, 2008), o que elimina as duas últimas condições à delimitação da faixa de APP, ou seja, a faixa não pode ser menor que $30 \mathrm{~m}$.

Devido à complexidade entorno do conceito, definição e diferenciação, sobretudo sob a análise geográfica, das áreas urbanas e rurais, emergindo ainda um termo intermediário, o periurbano (SPAROVEK \& COSTA, 2004), e à ausência de sedes administrativas em uma distância menor que cem metros da margem das represas, toda a área contida dentro desse espaço foi aceito para este estudo como área rural. Essa condição define a largura considerada APP no entorno dos reservatórios aqui estudados como cem metros.

\subsection{Conflitos de uso do solo na APP}

A distribuição espacial das classes de uso do solo e cobertura vegetal identificadas nas APPs pode ser observada na Figura 2. Foram identificadas 6 classes temáticas, as quais foram agrupadas da seguinte forma: água, correspondendo aos corpos d'água, ou seja, rios, represas, lagoas, etc.; mata e capoeira, caracterizada pela floresta de vegetação arbórea natural em diferentes estágios (primário, secundário - em regeneração); eucalipto, áreas com eucalipto manejado destinadas à silvicultura; pasto e agricultura, representada pelos campos naturais, pastagem e agricultura de pequeno porte; solo exposto, denotado pela presença de afloramentos rochosos, fraturas de erosão e superfícies recém desmatadas, colhidas ou preparadas ao plantio; e unidade urbana, ou seja, núcleos e aglomerados urbanos, estruturas isolados de concreto, etc. Os diferentes tamanhos das represas ocasionaram diferentes percentuais de cobertura vegetal e uso do solo, embora as mesmas classes estejam presentes no entorno de ambos os reservatórios.

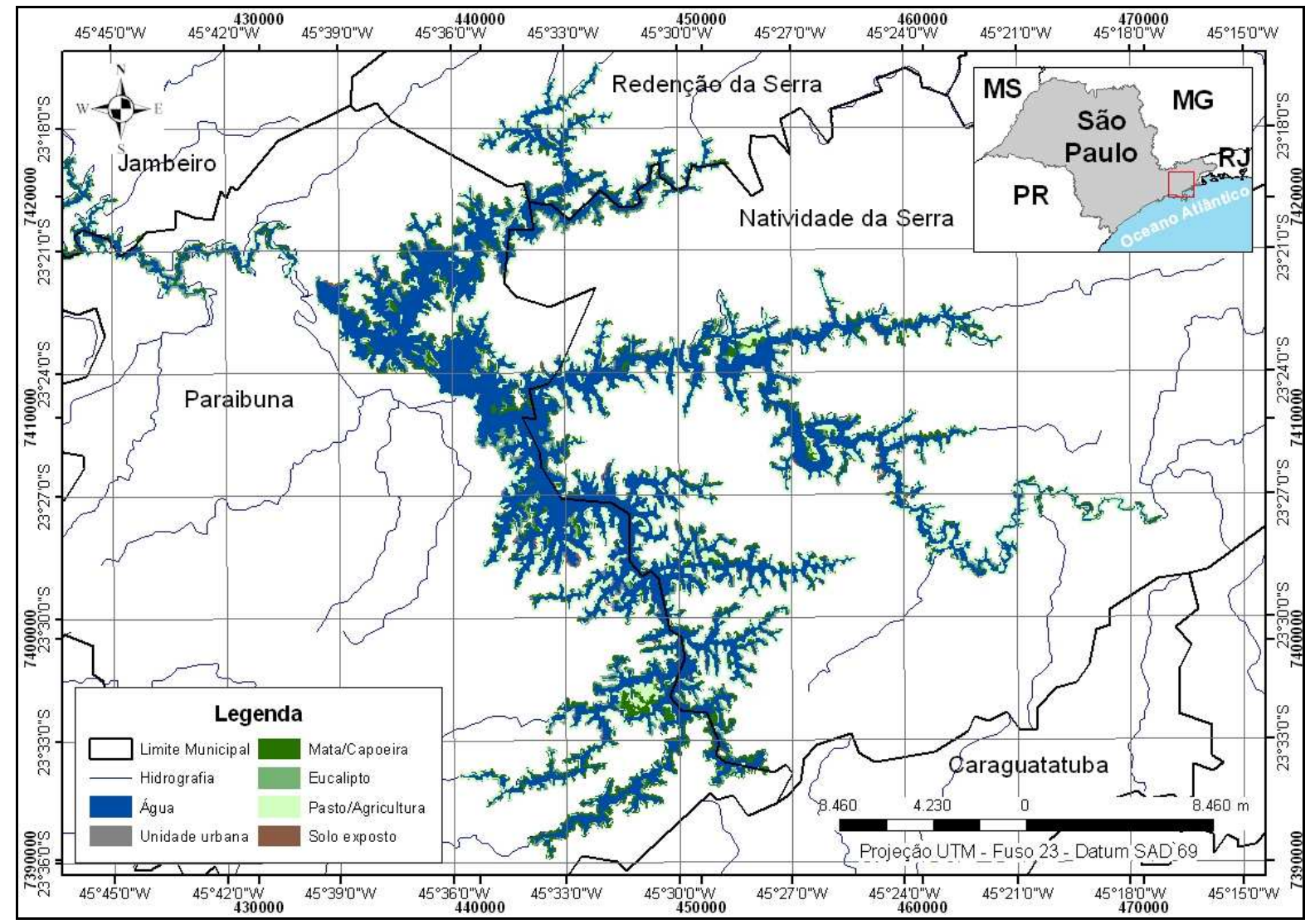

Figura 2 - Mapa de cobertura vegetal e uso do solo na APP da represa Paraibuna-Paraitinga. 
A área total do buffer ocupou 24.853,79ha, com 13.889,56ha pertencem a área da represa no nível d'água no momento do imageamento. Logo, a APP resultante nesse reservatório é de $10.964,23$ ha.

O percentual restante da classe água é representado pela presença de pequenos corpos d'água, os quais, conforme o Código Florestal, também deveriam possuir APP. Como estes corpos estão incluídos em uma área de APP, torna-se desnecessário a delimitação de uma APP específica para estes.

Observando a participação de cada município na APP da represa Paraibuna-Paraitinga, o destaque é de Natividade da Serra, o qual possui uma área de APP com aproximadamente 5.500ha (Figura 3). Complementam a APP do reservatório Paraibuna-Paraitinga, os municípios de Redenção da Serra e de Paraibuna.

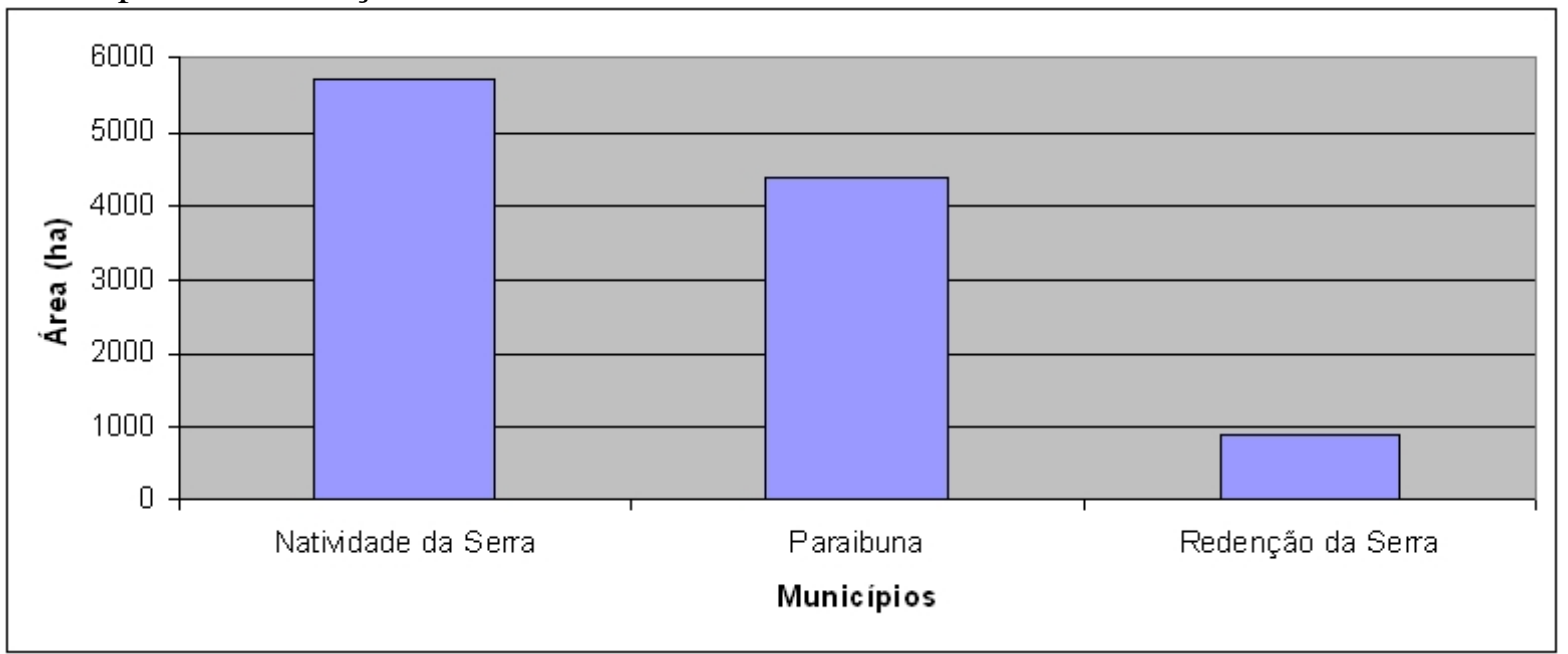

Figura 3 - Área de cada município pertencente à APP da represa Paraibuna-Paraitinga.

A APP da represa Paraibuna-Paraitinga demonstrou padrão de cobertura vegetal e uso do solo com predomínio da classe Pasto/Agricultura, seguida pela Mata/Capoeira, totalizando juntas $85,77 \%$ (Tab. 1).

TABELA 1 - Valores de cobertura vegetal e uso do solo na APP do entorno das represas Paraibuna-Paraitinga.

\begin{tabular}{|l|c|c|}
\cline { 2 - 3 } \multicolumn{1}{c|}{} & \multicolumn{2}{c|}{ Paraibuna-Paraitinga } \\
\hline Ćlasse & Área (ha.) & \% \\
\hline Unidade urbana & 1,46 & 0,01 \\
\hline Mata/Capoeira & 209,63 & 1,91 \\
\hline Eucalipto & 2654,30 & 24,21 \\
\hline Pasto/Agricultura & 1155,36 & 10,54 \\
\hline Solo exposto & 6750,06 & 61,56 \\
\hline Total & 193,42 & 1,76 \\
\hline
\end{tabular}

O padrão demonstrado pelas classes da APP da represa Paraibuna-Paraitinga que se enquadram nos territórios dos municípios que as circundam é semelhante ao apresentado até então, persistindo a classe Pasto/Agricultura como a mais representativa dentre as classes, seguido de mata/capoeira e eucalipto (Figura 4).

A presença do eucalipto está correlacionada com a produção de madeira em tora para papel, celulose e outras finalidades. Este é o único produto da silvicultura presente nos municípios estudados e gera uma renda anual de aproximadamente R $\$ 25.000 .000$ (IBGE, 2007). 


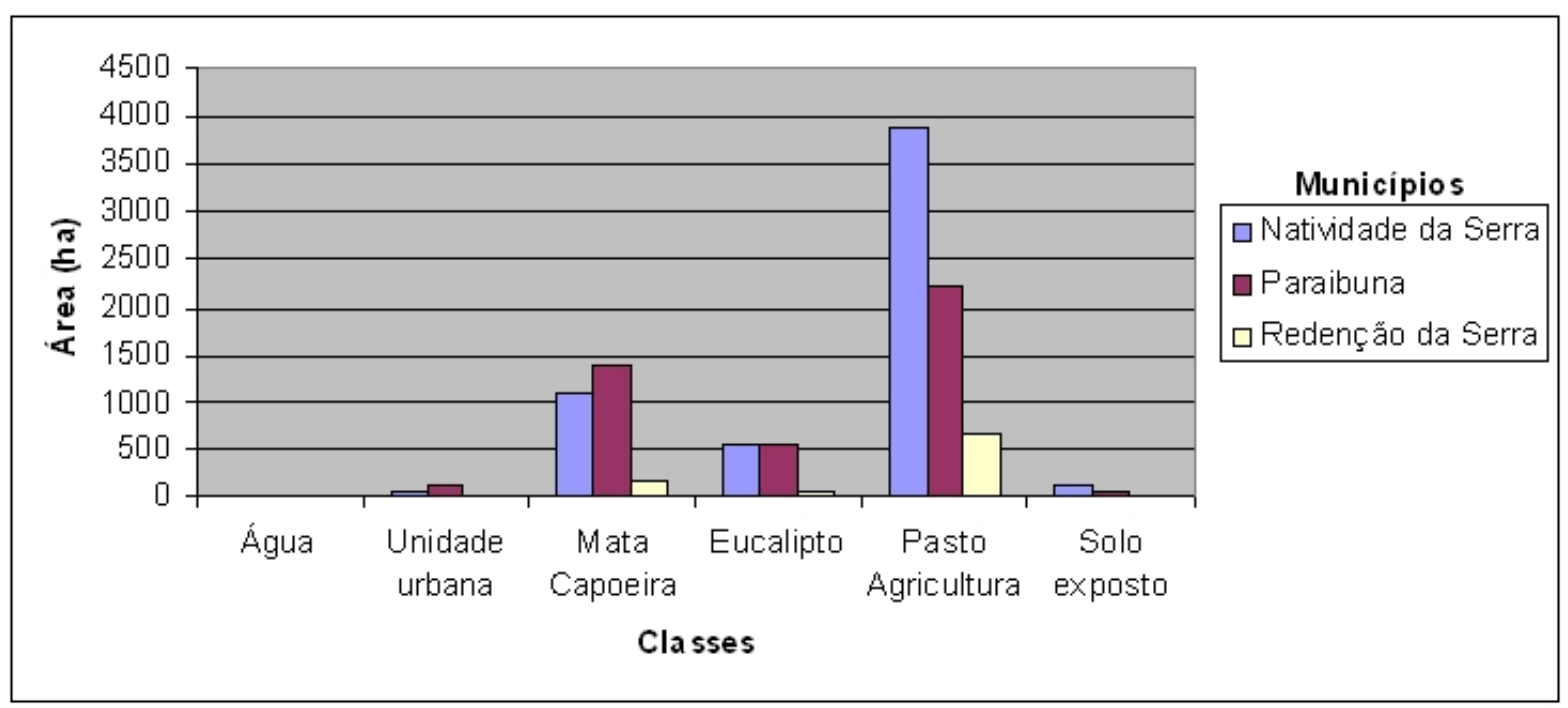

Figura 4 - Área por município das classes identificadas para a APP da represa Paraibuna-Paraitinga.

A Quarta classe que ocupa maior percentual de área na APP da represa ParaibunaParaitinga é a de unidades urbanas. Essa posição pode ser explicada pela presença da Rodovia dos Tamoios (SP-099), as estações hidroelétricas, e a instalações do segmento lazer.

A presença de solo exposto na área de estudo está correlacionada ao nível d'água no momento do imageamento pelo sensor TM/Landsat, o qual demonstrava estar abaixo do limite máximo, uma vez que muitas áreas de solo exposto estão localizadas nas margens deste reservatório. Quando não localizadas às margens das represas, está pautado na retirada da plantação de eucalipto e demais cultivos agronômicos e ao uso recreativo nas represas.

As classes eucalipto, solo exposto e unidade urbana refletem os recursos econômicos presentes nos municípios integrantes dessa região. Dentre as classes identificadas dentro da APP, a unidade urbana merece uma ressalva, pois essas áreas podem ser consideradas "não APP", cabendo, nesse caso, o que estiver disposto nos respectivos planos diretores e leis de uso do solo dos municípios.

\section{Considerações finais}

O uso de técnicas de geoprocessamento permitiu a execução da análise no entorno das represas Paraibuna-Paraitinga de forma rápida, precisa e com baixo custo financeiro. A replicação dessa metodologia em outras represas ou mesmo na dinâmica espaço-temporal da represa aqui estudada se faz necessária para que se possa ter conhecimento dos padrões de uso do solo no entorno dessas, bem como na evolução e possíveis cenários futuros conforme tendência observada.

Notou-se a existência de um déficit de aplicabilidade da legislação incidente sobre as APPs no entorno dos reservatórios Paraibuna-Paraitinga, resultando numa discrepância do uso e/ou cobertura do solo atual em relação àquela norteada pela legislação.

Esse modelo de uso/cobertura faz com que a maior parte da APP seja designada ao reflorestamento de espécies nativas e trás à reflexão qual o real objetivo da existência do Código Florestal brasileiro.

Por gerar recursos econômicos importantes aos municípios, oriundos, sobretudo, da silvicultura, do turismo e da agropecuária, um plano de manejo dessa área de faz necessário. Este deve ser realizado a partir de uma análise dos respectivos planos diretores e leis de uso do solo municipais, bem como na Resolução CONAMA no 369 de 28 de março de 2006, que dispõe sobre os casos excepcionais, de utilidade pública, interesse social ou baixo impacto ambiental, que possibilitam a intervenção ou supressão de vegetação em APP. 
A permanência do panorama atual no entorno das represas Paraibuna-Paraitinga é preocupante, uma vez que pode ter influência negativa direta na qualidade de água, prejudicando assim a principal função social de existência dessas represas, que é o abastecimento de água ao estado do Rio de Janeiro e demais cidades da bacia.

\section{Referências}

BRASIL. Decreto Federal no 23.793de 23 de janeiro de 1934. Aprova o Código Florestal que com este baixa. Disponível em: <http://www.planalto.gov.br/ccivil_03/Decreto/1930-1949/D23793.htm> Acesso em: 23 nov. 2008

BRASIL. Lei Federal no 4771, de 15 de setembro de 1965: institui o novo Código Florestal. Disponível em: $<$ http://wwwt.senado.gov.br/servlets/NJUR.Filtro?tipo=LEI\&secao=

NJUILEGBRAS\&numLei=004771\&data=19650915\&pathServer=www1/netacgi/nph-brs.exe\&seq=0 00>. Acesso em 26 set. 2003.

BRASIL. Resolução CONAMA no 302, de 20 de março de 2002. Dispõe sobre os parâmetros, definições e limites de Áreas de Preservação Permanente de reservatórios artificiais e o regime de uso do entorno. Disponível em: <http://www.mma.gov.br/port/ conama/legiabre.cfm?codlegi=298>. Acesso em $12 \mathrm{dez}$. 2008.

BRASIL. Resolução CONAMA n 369, de 28 de março de 2006. dispõe sobre os casos excepcionais, de utilidade pública, interesse social ou baixo impacto ambiental, que possibilitam a intervenção ou supressão de vegetação em Área de Preservação Permanente- APP. Disponível em:

<http://www.mma.gov.br/port/conama/legiabre.cfm?codlegi=489>. Acesso em 27 dez. 2008.

CÂMARA, G.; SOUZA, R. C. M.; FREITAS, U. M.; GARRIDO, J. SPRING: integrating remote sensing and GIS by object-oriented data modelling. Comput Graph, v. 20. p. 395-403.1996.

CHAVEZ JR., P. S.; BERLIN, G. L.; SOWERS, L. B. Statistical method for selecting Landsat MSS ratios. Journal of Applied Photographic Engineering, v. 8, p. 23-31, 1982.

DIAS, N. W.; MORAES, E. C.; NOVO, E. M. L. M.; ARAI, E.; CATELANI, C. S. Caracterização das águas da represa de Paraibuna com o uso de dados hiperespectrais. In: Simpósio Brasileiro De Sensoriamento Remoto, 13. (SBSR), 2007, Florianópolis. Anais...São José dos Campos: INPE, 2007. p. 3335-3342. CDROM; Disponível em: <http://urlib.net/dpi.inpe.br/sbsr@80/2006 /11.13.23.48>. Acesso em: 16 dez. 2008.

DGI/INPE. Divisão de Geração de Imagens/Instituto Nacional de Pesquisas Espaciais. Catálogo de Imagens. Disponível em <http://www.dgi.inpe.br/CDSR/>. Acesso em 23 jul. 2008.

EMBRAPA. Empresa Brasileira de Pesquisa Agropecuária. Sistema brasileiro de classificação de solos. Brasília: Embrapa Produção de informação, Rio de Janeiro, Embrapa Solos, 1999. 412p.

IBAMA. Instituto Brasileiro do Meio Ambiente e dos Recursos Renováveis. Sistema Compartilhado de Informações Ambientais - SisCom. Disponível em: <http://siscom.ibama.gov.br/>. Acesso em 03 mai 2008.

IBGE. Instituto Brasileiro de Geografia e Estatística. Cidades@. Disponível em: <http://www.ibge.gov.br/cidadesat/topwindow.htm?1>. Aceso: 14 out. 2007.

IBGE. Instituto Brasileiro de Geografia e Estatística. Produtos, Geociências. Disponível em: <http://www.ibge.gov.br/home/geociencias/default_prod.shtm>. Acesso em 05 mai 2008.

MARTINS, P. T. A. Análise das intervenções antrópicas no manguezal do Rio Cachoeira, Ilhéus, Bahia. 2008. Dissertação (Mestrado em Geografia) Núcleo de Pós-Graduação em Geografia, Universidade Federal de Sergipe, 2008.

NASA. National Aeronautics and Space Administration. GeoCover. Disponível em: <https:// zulu.ssc.nasa.gov/mrsid/mrsid.pl>. Acesso em 24 jul. 2008.

PRADO, R.B. Geotecnologias aplicadas à análise espaço-temporal do uso e cobertura da terra e qualidade da água do reservatório de Barra Bonita, SP, como suporte à gestão de recursos hídricos. São Carlos. Tese (Doutorado). Centro de Recursos Hídricos e Ecologia Aplicada, Escola de Engenharia de São Carlos, Universidade de São Paulo, 2004. 
Anais II Seminário de Recursos Hídricos da Bacia Hidrográfica do Paraíba do Sul: Recuperação de Áreas Degradadas, Serviços Ambientais e Sustentabilidade, Taubaté, Brasil, 09-11 dezembro 2009, IPABHi, p. 443-452.

(doi:10.4136/serhidro.58)

SÃO PAULO. Sistema de Informações para o Gerenciamento de Recursos Hídricos do Estado de São Paulo: Paraíba do Sul. Disponível em: <http://www.sigrh.sp.gov.br/sigrh/ ARQS/RELATORIO/CRH/1063/ugrhi_02_04.pdf> Acesso em 20 abr. 2008>.

SPAROVEK, Gerd; COSTA, Francisca Pinheiro da Silveria. Evolução urbana e da cobertura vegetal de Piracicaba-SP (1940-200). Caminhos da Geografia, Uberlândia, v. 5, n. 13, p. 65-88, 2004. 